\title{
Are age-of-acquisition effects on object naming due simply to differences in object recognition? Comments on Levelt (2002)
}

\author{
PATRICK BONIN, MARYLÈNE CHALARD, and ALAIN MÉOT \\ Université Blaise Pascal, Clermont-Ferrand, France \\ and \\ CHRISTOPHER BARRY \\ University of Essex, Colchester, England
}

\begin{abstract}
Levelt (2002) argued that apparent effects of word frequency and age of acquisition (AoA) reported in recent picture naming studies might actually be confounded effects operating at the level of object recognition, rather than relevant to theories of lexical retrieval. In order to investigate this issue, AoA effects were examined in an object recognition memory task (Experiments 1 and 2) and a word-picture verification task (Experiment 3) and compared with those found in naming tasks using the same pictures. Contrary to Levelt's concerns, the results of the three experiments show that the AoA effect on picture naming has a lexical origin and does not simply result from a possible confound of object identification times.
\end{abstract}

Object naming can be modeled as involving five major processing stages that are organized broadly sequentially but may operate in cascade (see, e.g., Humphreys, Riddoch, \& Quinlan, 1988): perceptual analysis $\rightarrow$ object recognition $\rightarrow$ semantic comprehension $\rightarrow$ name retrieval $\rightarrow$ word articulation. A large number of studies have been conducted to investigate the factors that affect object naming times. These factors include characteristics of the pictures used (e.g., visual complexity and image agreement), aspects of the semantic features of the objects (e.g., whether they are living things or artifacts), and variables that relate to the names of the objects (e.g., word frequency and phonological length). (There are, in addition, numerous studies of experimental manipulations that affect naming times, such as repetition priming.) Psycholinguistic variables (e.g., word frequency and age of acquisition, or AoA) have been studied with the motivation of informing our understanding of the processes involved in word retrieval in speech production, the fourth of the five major processes involved in object naming. Many studies have reported effects of word frequency on object naming times (e.g., Jescheniak \& Levelt, 1994), and in recent studies the effects of word frequency have been contrasted with those of object name AoAs. These two variables correlate, since words used more frequently in adulthood tend to be learned earlier in life, and so it is necessary to deter-

Correspondence concerning this article should be addressed to P. Bonin, Laboratoire de Psychologie Sociale et Cognitive (LAPSCO/CNRS 6024), Université Blaise Pascal, 34, avenue Carnot, 63037 ClermontFerrand, France (e-mail: patrick.bonin@srvpsy.univ-bpclermont.fr).

Note-This article was accepted by the previous editorial team, when Colin M. MacLeod was Editor. mine which is of primary importance. Whereas AoA has generally not been controlled in studies reporting effects of frequency (e.g., Oldfield \& Wingfield, 1965), every study in which AoA has been examined (and frequency controlled) has found it to exert a reliable effect on object naming times. For example, in semifactorial studies both Barry, Hirsh, Johnston, and Williams (2001) and Bonin, Fayol, and Chalard (2001) found a reliable effect of AoA on object naming times when frequency was controlled, but no effect of frequency when AoA was controlled. A number of multiple regression studies have found effects of both AoA and frequency (e.g., Barry, Morrison, \& Ellis, 1997; Bonin, Peereman, Malardier, Méot, \& Chalard, 2003; Ellis \& Morrison, 1998; Lachman, 1973; Lachman, Shaffer, \& Hennrikus, 1974).

The reported effects of both AoA and frequency on naming times have generally been interpreted as affecting the process of lexical retrieval. For example, Alario, Costa, and Caramazza (2002a) studied the production of determiner-adjective-noun phrases (e.g., the red kite) as descriptions of pictures and found additive effects of the word frequency of the adjectives and nouns, with faster naming responses to high-frequency words. They interpreted these effects as being problematic for theories that propose that frequency affects the level of phonological encoding of naming and that the phonological word (e.g., the red is a phonological word) is the minimal unit of phonological encoding. According to these theories, frequency effects in noun phrases should be observed on adjectives and not on nouns, which belong to a different phonological word.

In his critique of Alario et al. (2002a), Levelt (2002) argued that a "serious omission" of the study was that it did not control for the speed of object recognition, since 
pictured objects with low-frequency names may be less recognizable than those with high-frequency names. In other words, Levelt argued that reported frequency effects on naming times may actually have been operating at the stage of object recognition rather than at that of lexical retrieval, but may be "passed on" to be observed in naming latencies; they would "just signal a visual process instead of a lexical one" (p. 668). Levelt applied the same general criticism to the studies of AoA effects on object naming by Bonin et al. (2001) and Barry et al. (2001), which involved the production of single words rather than short phrases. Both studies revealed an AoA effect but no frequency effect, but neither study ensured that the items with names acquired early and those with names acquired late were matched on object recognition speed. Levelt reasoned that it is possible that ratings of AoA are correlated with object recognition time. He argued that "if recognition speed did do the work in these experiments, then they do not tell us anything about lexical access" (p. 669). ${ }^{1}$ In their reply to Levelt, Alario, Costa, and Caramazza (2002b) conceded that his alternative interpretation of the frequency effect is logically possible but argued that the available empirical evidence makes it unlikely. They noted that studies that have shown an effect of word frequency on naming times but not on categorization times (e.g., Jescheniak \& Levelt, 1994; Morrison, Ellis, \& Quinlan, 1992) have assumed that categorizing pictures does not require name retrieval. Also, they pointed out that frequency effects on naming have been found in patients with deficits unambiguously located at the level of name retrieval and not at a semantic level of object identification.

The primary purpose of this article is to address this important (but essentially methodological) issue raised by Levelt (2002) and to seek some empirical resolution of it with respect to AoA effects on object naming. In essence, Levelt argued that before one can conclude that a variable affects lexical retrieval in picture naming, it is necessary to establish that it does not affect object recognition. As with any potential confound, it is vital to assess its impact empirically. Before we can accept Levelt's criticism of AoA studies, it must be established that the AoA effects observed in naming times will vanish if object identification time is taken into account.

Levelt (2002) helpfully reviewed three tasks that might be used to assess effects operating at the level of object recognition. The first is the object decision task introduced by Kroll and Potter (1984). In this task, participants judge whether each of a series of individually presented pictures is a real object or a nonobject (and respond by pressing one of two response keys). Response times (RTs) to pictures of real objects are assumed to index the visual processing of the pictures, access to stored structural knowledge about the objects (Humphreys et al., 1988), and perhaps also access to semantic representations. Vitkovitch and Tyrrell (1995), Moore, Smith-Spark, and Valentine (2004), and Holmes and Ellis (2006) have reported AoA effects in this task, with advantages for items with names acquired early. The object decision task may be seen as being similar to the lexical decision task used to study word recognition and suffers from similar possible problems. Lexical decision times are typically longer than word naming times and are affected both by the nature of the nonword distractors and by postrecognition, semantic variables. Since object decision latencies are sometimes as long as picture naming latencies, ${ }^{2}$ the task may not necessarily be a "pure" index of perceptual object recognition. Indeed, Holmes and Ellis found an effect of typicality, in addition to one of AoA, in the object decision task; objects rated as being more typical exemplars of their superordinate categories (e.g., animals, birds, musical instruments, tools) were responded to faster than less typical objects. This suggests that object decision times involve accessing semantic representations in addition to the stored structural descriptions responsible for perceptual object recognition. Given this, the object decision task may not be an ideal one for testing effects operating solely at the level of object recognition.

A second task considered by Levelt (2002) is what he calls the object recognition task (see Levelt et al., 1991), although it is really a version of an object recognition memory task. Participants must first learn a set of nontarget pictures. Then, these pictures are intermixed with a set of target or experimental pictures, and participants must make "old" responses to the learned nontarget pictures and "new" responses to the previously nonpresented target pictures. This procedure removes possible contamination of priming from the learned items to RTs to the "new" target pictures (which are understood to reflect object recognition times). We shall use this procedure in Experiments 1 and 2 to examine AoA effects on object recognition.

A third task is the word-picture verification task, in which participants are presented with a word (which may be either spoken or printed) followed by a picture and must decide if the two match (and respond "yes" or "no" either by pressing an appropriate response key or by making a vocal response). Chalard and Bonin (2006) found no AoA effect in this task for matching words and pictures, although there was an AoA effect for naming the same pictures. One possible problem with this task that Levelt (2002) identified is that for "yes" responses the word may have facilitated recognition of the picture. In Experiment 3, we shall overcome this possible problem by using as target pictures those that require a "no" (or mismatching) response.

In Experiment 1, we examined possible AoA effects in the object recognition memory task. Experiment 1 adopts a factorial study in which objects with names acquired early are compared with those with names acquired later. The stimuli were those used by Bonin et al. (2001), who found an AoA effect in French for both spoken and written naming times for these pictures. In Experiments 2 and 3, we operationalized AoA in terms of frequency trajectory, as recommended by Zevin and Seidenberg (2002) in their discussion of AoA and word frequency effects on word reading times. Frequency trajectory refers to the distri- 
bution of word frequency over a reader's lifetime. Words with high-to-low-frequency trajectories occur frequently in texts for children but less commonly in adult texts (and so should be acquired early). In contrast, words with lowto-high-frequency trajectories occur rarely in children's texts but are more common in adult texts (as are words acquired late). With the same object recognition memory task, Experiment 2 adopts a factorial design with a subset of the stimuli from a larger multiple regression study of naming times by Bonin, Chalard, Méot, and Fayol (2002). In Experiment 3, the word-picture verification task was used and a multiple regression design was adopted to examine AoA and frequency effects on object recognition.

\section{EXPERIMENT 1 \\ Object Recognition Times to the Items From Bonin et al. (2001)}

The stimuli used by Bonin et al. (2001) in their Experiments 1 and 2 were presented in the object recognition memory task. Bonin et al. (2001) compared oral and written picture naming times for two sets of pictures matched for word frequency and a range of other variables (see Table 1): one set with names acquired early in life and the other with names acquired later in life. There were reliable AoA effects for both naming tasks, with shorter naming times to pictures with names acquired early. Experiment 1 was conducted to establish whether or not there are differences in the object recognition times for these two sets of items and, if so, whether the observed difference in naming times could be reducible to differences in object recognition times.

\section{Method}

Participants. Twenty-four psychology students (3 male and 21 female, 18-24 years of age, $M=19.7$ years) from Blaise Pascal University received course credit for participating in the experiment. All were native speakers of French and had normal or corrected-tonormal vision.

Stimuli. The experimental items used in Bonin et al.'s (2001) Experiments 1 and 2 served as stimuli. There were two sets of 18 pictures taken from Cycowicz, Friedman, Rothstein, and Snodgrass (1997). One set consisted of pictures with names acquired early and the other of pictures with names acquired late. The AoA measures were taken from ratings provided by adults (Alario \& Ferrand, 1999).

The two sets were matched for name agreement; image agreement; visual complexity; word frequency; numbers of letters, phonemes, and syllables; and bigram frequency. The two sets were not matched a priori on conceptual familiarity or imageability, and so these factors were included as covariates in the item analyses. Another 36 pictures (which also contrasted on AoA) were used for the learning stage and so required "yes" responses in the recognition test.

Apparatus. The experiment was performed with PsyScope Version 1.2 (Cohen, MacWhinney, Flatt, \& Provost, 1993) and run on a Power Macintosh. The computer controlled the presentation of the pictures and recorded RTs.

Procedure. The participants were tested individually. In the first (learning) stage of the experiment, the participants were shown a series of 36 pictures. In each trial, a ready signal (*) was first presented for $500 \mathrm{msec}$, and then a picture was presented for $1.5 \mathrm{sec}$. The participants were instructed to remember each picture. The next trial began after a 2 -sec blank screen. In the second (recognition)
Table 1

Characteristics of the Items Used in Experiment 1

\begin{tabular}{lcc}
\hline \multicolumn{1}{c}{ Variable } & \multicolumn{2}{c}{$\begin{array}{c}\text { Age of } \\
\text { Acquisition }\end{array}$} \\
\cline { 2 - 3 } & Early & Late \\
\hline Rated AoA (in years; & 1.50 & 2.60 \\
$\quad$ Alario \& Ferrand, 1999) & 96.5 & 94.2 \\
Percent name agreement & 3.40 & 3.30 \\
Image agreement (1-5) & 3.00 & 3.00 \\
Visual complexity (1-5) & 1.51 & 1.34 \\
Word frequency (log) & 3.60 & 2.60 \\
Familiarity (1-5) & 3.40 & 2.70 \\
Imageability (1-5) & 6.1 & 6.3 \\
Number of letters & 4.3 & 4.7 \\
Number of phonemes & 1.7 & 1.8 \\
Number of syllables & 3.06 & 2.97 \\
Bigram frequency (log) & & \\
\hline
\end{tabular}

stage of the experiment, the participants were told that they would see pictures, some of which had been shown during the learning phase ("old" pictures) and others that had not been previously presented ("new" pictures). They had to press a button on the keyboard as quickly as possible whenever they recognized a picture as being "new" and make no response if the picture was "old." We chose this go/no-go procedure instead of a binary "old"-"new" response procedure because the former seems to require fewer processing demands than the latter (Perea, Rosa, \& Gómez, 2002). The critical sets of 18 early-AoA and 18 late-AoA experimental pictures used in Bonin et al.'s (2001) study were assigned the "new" response. Trials had the same structure as those in the learning stage except that the pictures disappeared after the participant made a "new" response (or after $1.5 \mathrm{sec}$ if the participant considered that the picture was "old").

\section{Results}

The RTs of correct "new" responses, their $S D$ s, and the percent error rates to the experimental (or target) set of pictures with names acquired early and the set of pictures with names acquired late are presented in Table 2. For all analyses, the conventional level of .05 for statistical significance was adopted.

Pictures with names acquired early were responded to as being "new" faster than those with names acquired late $\left[F_{1}(1,23)=26.73, M S_{\mathrm{e}}=937.83 ; F_{2}(1,32)=4.74\right.$, $\left.M S_{\mathrm{e}}=2,014.43\right]$. There was no reliable AoA effect on error rate $(F \mathrm{~s}<1)$. The AoA effect on recognition times (45 msec) was less than the $147-\mathrm{msec}$ effect reported by Bonin et al. (2001) for verbal naming.

Overall, there was a $9.6 \%$ miss rate to "new" items (i.e., failure to give a "go" response to experimental items) and a $11.92 \%$ false alarm rate to the pictures shown during the

Table 2

Results of Experiment 1: Mean Response Times (RTs, in Milliseconds, With SDs) and Percent Error Rates in Object Recognition

\begin{tabular}{cccc}
\hline $\begin{array}{c}\text { Age of } \\
\text { Acquisition }\end{array}$ & RT & $S D$ & \%Error \\
\hline Early & 751 & 79 & 9.26 \\
Late & 796 & 90 & 9.95 \\
\hline
\end{tabular}


learning phase (i.e., incorrectly providing a "go" response to "old" items).

The naming latencies for the objects with names acquired early and those with names acquired late, reported by Bonin et al. (2001), were then reanalyzed with the recognition times of the objects obtained in the present experiment used as a covariate. The important conclusion of this analysis is that the AoA effect found in spoken picture naming latencies was still reliable when recognition times were introduced as a covariate $\left[F(1,31)=17.49, M S_{\mathrm{e}}=\right.$ $65,321.11]$.

\section{Discussion}

Experiment 1 revealed a reliable effect of AoA on the time taken to make "new" responses in the object recognition memory task: Objects with names acquired early were responded to $45 \mathrm{msec}$ faster than those with names acquired late. However, this AoA effect had only one third of the magnitude of that reported by Bonin et al. (2001) for verbal object naming $(147 \mathrm{msec})$. Furthermore, the AoA effect was proportionately smaller for recognition than for naming: It represented $5.8 \%$ of the overall mean recognition times (accounting for 45 out of $774 \mathrm{msec}$ ) but $17.8 \%$ of the overall mean oral naming times (accounting for 147 out of $827 \mathrm{msec}$ ).

The fact that in Experiment 1 we found an AoA effect on recognition times suggests that Levelt's (2002) concern that the AoA effect on naming might be confounded by an AoA effect on object recognition has some foundation, at least for the stimuli used by Bonin et al. (2001). However, it cannot simply be the case that differences in recognition speed did do the work in Bonin et al.'s (2001) naming results: The AoA effect on naming was still reliable when the recognition times of the pictures were taken into account in the ANCOVAs. AoA effects on object naming are not simply reducible to (or "passed on" from) real (if smaller) AoA effects on object recognition. ${ }^{3}$ Therefore, Bonin et al.'s (2001) major theoretical conclusion that AoA effects on picture naming operate at the level of lexical retrieval is not undermined by the results of Experiment 1 .

\section{EXPERIMENT 2 Frequency Trajectory in Object Recognition and Naming}

Within the field of word reading, Zevin and Seidenberg (2002) raised some important concerns about the use of word frequency norms that do not take into account the frequency with which words are encountered during childhood. They argued that frequency measures that take childhood frequencies into account provide more reliable estimates of the frequency of words encountered over the life span - that is, the cumulative frequency of words. For American English, the Zeno (1995) norms meet this criterion. Zevin and Seidenberg showed that using the Zeno norms in multiple regression analyses resulted in the elimination of an AoA effect in a number of word reading studies. Zevin and Seidenberg also questioned the use of both rated and objective measures of AoA in predicting adult performance in word processing tasks. In particular, they argued that the use of objective AoA measures leads to the circularity problem of predicting adult performance from the ages at which children can name objects, which is itself a performance measure. Their suggested solution is to operationalize AoA in terms of a word's frequency trajectory, which refers to changes in frequency over age. For example, the word fairy is frequently encountered during childhood, but its frequency declines in adulthood, whereas the opposite is true for the word tax. They argued that some words will be acquired earlier in life because they are encountered more frequently than others in the texts to which children are exposed while learning to read. Indeed, frequency trajectory is a reliable determinant of the age/order of acquisition of words in both French and English (Bonin, Barry, Méot, \& Chalard, 2004; Zevin \& Seidenberg, 2002). Zevin and Seidenberg proposed that frequency trajectory should be used to test the influence of age-limited learning effects (or AoA effects) in lexical processing in adults because it is not a behavioral measure (since it is based on objective measures of word frequency) and so avoids the circularity problem.

From Zevin and Seidenberg's (2002) connectionist modeling work, age-limited learning effects should be found only in tasks in which what is learned about items acquired early does not carry over to those acquired late. Thus, frequency trajectory effects should be found in picture naming (in which the mapping relationships between semantic representations and names is largely arbitrary) but not in reading words aloud in orthographies such as those of French and English, in which the mappings between orthographic and phonological codes are quasi-systematic. (This pattern of results was confirmed by Bonin et al., 2004.) In Experiment 2, we examined frequency trajectory effects in the object recognition memory task. If object recognition involves arbitrary mappings between visual perceptual representations of pictures and stored structural representations, then an effect of frequency trajectory on object recognition performance should be observed. We selected two sets of pictures from those in the larger multiple regression study of object naming reported by Bonin et al. (2002): one set of objects whose names have high-to-low-frequency trajectories (i.e., names acquired early in life) and one set of objects whose names have low-to-high-frequency trajectories (i.e., names acquired later in life). The two sets were matched for the cumulative frequency of their names and for a range of other relevant variables.

\section{Method}

Participants. Twenty-four psychology students ( 2 male and 22 female, $18-23$ years of age, $M=19.3$ years) from the same pool as those involved in Experiment 1 participated in this experiment and received course credit.

Stimuli. The experimental stimuli consisted of two sets of 26 pictures selected from the 237 used in Bonin et al.'s (2002) naming study. One set of pictures had names with high-to-low-frequency trajectories, and the other set had names with low-to-high-frequency trajectories. In order to compute frequency trajectory and cumula- 
tive frequency, the FRANTEXT frequency measures (taken from LEXIQUE; New, Pallier, Ferrand, \& Matos, 2001) and the MANULEX child frequency measures (Lété, Sprenger-Charolles, \& Colé, 2004) were used. The LEXIQUE database is a corpus of over 31 million words covering all parts of speech of the French language, and MANULEX provides frequency counts of words from a corpus of 1.9 million words in the main French primary school reading books for four levels (first grade, second grade, third to fifth grades, and all grades). For each object name, the FRANTEXT (adult) and MANULEX (child) frequency values were log transformed and standardized (using $z$ scores). Frequency trajectory was computed as the difference between the $z$ scores associated with the two measures of frequency (FRANTEXT minus MANULEX; see Bonin et al., 2004). The words with high-to-low-frequency trajectories (e.g., the French words for pig, clown, and fox) had higher child and lower adult frequencies, and those with low-to-high-frequency trajectories (e.g., the French words for candle, cigarette, and ruler) had lower child and higher adult frequencies. The words used in the experiment are listed in the Appendix. The two sets were matched on the cumulative frequency of the names (which was computed by adding the $z$ scores of the FRANTEXT and MANULEX frequency measures), name agreement, image agreement, visual complexity, conceptual familiarity, imageability, word length (in terms of numbers of letters, phonemes, and syllables), and bigram frequency. Table 3 shows the mean values on these various dimensions for the two sets as well as the adult ratings of the AoAs of the names (taken from Alario \& Ferrand, 1999). As can be seen, the words with high-to-lowfrequency trajectories were indeed rated as acquired reliably earlier than those with low-to-high-frequency trajectories. Also shown in Table 3 are the spoken and written picture naming latencies for these items, taken from the larger multiple regression study reported by Bonin et al. (2002). The pictures whose names had high-to-lowfrequency trajectories were named reliably faster than those with low-to-high-frequency trajectories.

Another set of 52 pictures was used for the learning stage of the experiment: Twenty-six had names with low-to-high-frequency trajectories, and 26 had names with a high-to-low-frequency trajectories. The characteristics of these items (which required an "old" response in the recognition stage of the experiment) were similar to those of the experimental items.

Procedure and Apparatus. The procedure and apparatus were the same as in Experiment 1.

\section{Results}

The mean RTs of correct "new" responses in the recognition task, their $S D$ s, and percent error rates to the experimental pictures are presented in Table 4. There were no reliable differences between the two sets of items on either RTs or error rates (all $F \mathrm{~s}<1$ ). Note that accuracy in the recognition memory task was quite high, even though the participants had to learn more pictures. There was an $11 \%$ error rate to new items (defined as failure to give a "go" response) and an $18.83 \%$ error rate to old items (defined as incorrectly providing a "go" response).

\section{Discussion}

In Experiment 2, it was found that when AoA was operationalized in terms of frequency trajectory (as advocated by Zevin \& Seidenberg, 2002) and the names were matched for cumulative frequency (along with a range of other potentially relevant variables), there was no effect on object recognition memory times. However, there were clear effects of frequency trajectory on written and spoken naming latencies for the pictures in Bonin et al.'s
Table 3

Characteristics of the Items Used in Experiment 2

\begin{tabular}{lccc}
\hline & \multicolumn{2}{c}{ Frequency Trajectory } & \\
\cline { 2 - 3 } \multicolumn{1}{c}{ Variable } & High to Low & Low to High & $p$ \\
\hline Frequency trajectory $(z$ score) & -0.89 & 0.89 & .001 \\
Cumulative frequency $(z$ score) & 0.16 & -0.16 & n.s. \\
Rated AoA (in years; & & & \\
$\quad$ Alario \& Ferrand, 1999) & 1.87 & 2.33 & .001 \\
Percent name agreement & 93 & 95 & n.s. \\
Image agreement (1-5) & 3.53 & 3.64 & n.s. \\
Visual complexity (1-5) & 3.20 & 3.09 & n.s. \\
Familiarity (1-5) & 2.64 & 3.17 & n.s. \\
Imageability (1-5) & 4.67 & 4.57 & n.s. \\
Number of letters & 6.04 & 6.27 & n.s. \\
Number of phonemes & 4.54 & 4.62 & n.s. \\
Number of syllables & 1.85 & 1.85 & n.s. \\
Bigram frequency (log) & 3.01 & 3.02 & n.s. \\
Spoken naming latency (msec) & 968 & 1,049 & \\
Written naming latency (msec) & 1,216 & 1,368 & \\
\hline
\end{tabular}

(2002) study. The results of Experiment 2 therefore satisfy Levelt's (2002) recommended criterion for an effect to be attributed validly to lexical retrieval rather than to visual identification processes: There was a frequency trajectory effect (or an AoA effect) on object naming for a set of items that were equated on their object recognition times. Therefore, we can conclude that AoA affects the process of lexical retrieval in object naming.

\section{EXPERIMENT 3 \\ Multiple Regression Analysis of Word-Picture Verification Times}

In several object naming studies, regression analyses have been applied to the naming times for large numbers of pictures (Alario et al., 2004; Barry et al., 1997; Bonin et al., 2002; Chalard, Bonin, Méot, Boyer, \& Fayol, 2003; Cuetos, Ellis, \& Alvarez, 1999; Snodgrass \& Yuditsky, 1996). The strongest determinants of naming speed in these studies include name agreement (which refers to the percentage of participants who produce the same name to a picture) and AoA (see Alario et al., 2004, Table 4). One way of addressing the issue of whether AoA effects or frequency effects on naming may be partly or entirely due to visual object recognition processes is to determine to what extent the variables that have generally been found to affect picture naming times also affect object identification times. Alario et al.'s (2004) review showed that the variables assumed to index perceptual object recognition processes (and/or access to semantics) were not found to be strong, reliable, or consistent determinants of picture

Table 4

Results of Experiment 2: Mean Response Times (RTs, in Milliseconds, With $S D s$ ) and Percent Error Rates in Object Recognition

\begin{tabular}{cccc}
\hline Frequency Trajectory & RT & $S D$ & \%Error \\
\hline Low to high & 805 & 88 & 10.90 \\
High to low & 801 & 82 & 11.06 \\
\hline
\end{tabular}


naming speed. For instance, visual complexity-which refers to ratings of the number of lines and "details and intricacy" in pictures (Snodgrass \& Vanderwart, 1980) has, quite reasonably, been assumed to affect initial visual recognition processes. However, Alario et al. (2004) found that visual complexity was reliable in only two of the seven picture naming studies they reviewed that included it in their regression analyses. Familiarity refers to ratings of how usual or unusual the concepts represented by the pictures' referents are in terms of people's realm of experience ${ }^{4}$ and so it can be seen as a subjective index of how often we encounter instances of objects. Levelt (2002) reasoned that pictures with low-frequency names might be less recognizable than those with high-frequency names, and that it may be even more likely that pictures with low familiarity ratings are less recognizable than those with high familiarity ratings. However, Alario et al. (2004) noted that rated familiarity was reliable in only three of the eight studies in which it was considered.

In Experiment 3, we adopted a multiple regression design in order to determine to what extent frequency trajectory, word frequency, and a number of other variables might affect object identification times in the word-picture verification task, in which participants are required to decide as quickly as possible whether a printed word presented before a picture matches the name of that picture. Following Levelt's (2002) advice, the critical, experimental pictures in Experiment 3 did not match the preceding word (and so all required a "different" response) in order to reduce the possibility of contamination from any semantic priming of object recognition times.

The goal of Experiment 3 was to assess Levelt's (2002) suspicion that AoA and word frequency effects observed in certain studies of picture naming might be due to a confound with the perceptual difficulty of the pictures. Wingfield (1968) used a version of the verification task to determine whether the frequency effect found in picture naming was due to lexical or perceptual recognition processes, and his findings supported a lexical interpretation. The results of Experiment 3 will also be used to reanalyze the naming times (reported by Bonin et al., 2002) to the same experimental pictures.

\section{Method}

Participants. The participants were 34 psychology students ( 3 male and 31 female, $18-38$ years of age, $M=20.2$ years) from the same pool as those involved in Experiments 1 and 2.

Stimuli. The critical stimuli (i.e., those to be verified as "different") were 203 pictures taken from the Snodgrass and Vanderwart (1980) database for which spoken picture naming RTs were available from the Bonin et al. (2002) study. An additional set of 203 pictures, taken from the larger Bonin, Peereman, et al. (2003) database, was used for the "same" responses.

For each picture, we had values for the variables of image agreement (i.e., the degree to which the mental image formed by the participants in response to the picture's name matches the picture's appearance), visual complexity, and conceptual familiarity; there was also a measure of percent name agreement. All of these measures were taken from Alario and Ferrand (1999). For the names of the objects, we collected ratings of imageability, or the ease with which the name arouses a mental image (from Bonin, Méot, et al., 2003), measures of name length (in number of phonemes), and both the cumulative frequency and frequency trajectory of each name. The dependent variable was the mean RT for each item averaged over participants.

Apparatus. The apparatus was the same as that used in Experiments 1 and 2 .

Procedure. The participants were tested individually. They were told that they would see a printed word followed by a picture and were instructed to decide as quickly as possible whether the word denoted the same concept as the one depicted by the picture. The participants responded by pressing one of two response buttons, labeled "same" and "different." Each trial began with a 500-msec warning signal $(*)$, which was followed by a printed word (presented for $1 \mathrm{sec}$ ). After a 1-sec interstimulus interval, a picture was presented and remained on the screen until the participant responded. There was then a $2-\mathrm{sec}$ intertrial interval.

\section{Results}

Trials on which the participants gave incorrect responses were discarded, and RTs more than two SDs above the participant and item means were excluded. Overall, $8.53 \%$ of all trials were discarded for these reasons. In addition, one item ( prise/plug) was eliminated from all analyses because it was a marked outlier.

Table 5 shows the intercorrelations between the wordpicture verification RTs (for "no" responses) from Experiment 3 , the picture naming latencies from Bonin et al. (2002), and the other characteristics of the pictures and their names. Three variables had significant correlations with both naming latencies and verification RTs: frequency trajectory, image agreement, and imageability. Picture naming latencies also correlated reliably with cumulative frequency, AoA, name agreement, and conceptual familiarity.

Multiple Regression Analysis 1. In this multiple regression analysis, object verification time was the dependent variable and the predictors were cumulative frequency, frequency trajectory, imageability, conceptual familiarity, name agreement, image agreement, visual complexity, and number of phonemes. (This set of independent variables is consistent with those of most studies of picture naming in which a multiple regression approach was adopted; see Alario et al., 2004.) The overall result of the simultaneous regression analysis was significant $\left(R^{2}=.093, p<.05\right)$. Table 6 shows that the only variable that made a significant contribution to correct "different" verification times was image agreement. The same pattern of results was obtained when adult ratings of AoA (Alario $\&$ Ferrand, 1999) were included instead of frequency trajectory, and when a measure of only adult frequency (New et al., 2001) was included instead of the measure of cumulative frequency.

Multiple Regression Analysis 2. In this analysis, the dependent variable was the picture naming latencies for the experimental items (Bonin et al., 2002) and the independent variables were those included in the first regression analysis plus object verification times. The overall result of the simultaneous regression analysis was significant $\left(R^{2}=.378, p<.001\right)$. The independent variables that 
Table 5

Correlation Matrix of Verification Times (From Experiment 3), Picture Naming Times (From Bonin et al., 2002), and 10 Object and Lexical Variables

\begin{tabular}{|c|c|c|c|c|c|c|c|c|c|c|c|}
\hline & PNT & Freq & CumF & FTraj & AoA & Imag & Fam & NA & IA & $\mathrm{VC}$ & Phon \\
\hline VT & $.160^{*}$ & .035 & -.049 & $.203^{*}$ & .070 & $-.173^{*}$ & .073 & -.056 & $-.191^{*}$ & -.065 & -.085 \\
\hline PNT & & $-.275^{*}$ & $-.363^{*}$ & $.150^{*}$ & $.483^{*}$ & $-.433^{*}$ & $-.291^{*}$ & $-.294^{*}$ & $-.195^{*}$ & .137 & .061 \\
\hline Freq & & & $.919^{*}$ & $.394^{*}$ & $-.518^{*}$ & .102 & $.538^{*}$ & .080 & $-.231^{*}$ & $-.190^{*}$ & $-.332^{*}$ \\
\hline CumF & & & & .000 & $-.662^{*}$ & $.248^{*}$ & $.419^{*}$ & .047 & $-.212^{*}$ & -.078 & $-.346^{*}$ \\
\hline FTraj & & & & & $.230^{*}$ & $-.321^{*}$ & $.386^{*}$ & .092 & -.091 & $-.298^{*}$ & -.037 \\
\hline AoA & & & & & & $-.519^{*}$ & $-.509^{*}$ & -.121 & .101 & $.198^{*}$ & $.267^{*}$ \\
\hline Imag & & & & & & & $.222^{*}$ & .118 & $.189^{*}$ & -.001 & .078 \\
\hline Fam & & & & & & & & .040 & $-.160^{*}$ & $-.492^{*}$ & -.077 \\
\hline NA & & & & & & & & & $.205^{*}$ & -.080 & .061 \\
\hline IA & & & & & & & & & & .021 & .081 \\
\hline $\mathrm{VC}$ & & & & & & & & & & & .049 \\
\hline
\end{tabular}

Note-VT, verification times in Experiment 3; PNT, picture naming times (from Bonin et al., 2002); Freq, word frequency (log transformed, from New et al., 2001); CumF, cumulative frequency; FTraj, frequency trajectory; AoA, age of acquisition (in years, from Alario \& Ferrand, 1999); Imag, imageability ratings (from Bonin, Méot, et al., 2003); Fam, conceptual familiarity ratings; NA, name agreement; IA, image agreement; VC, visual complexity (all from Alario \& Ferrand, 1999); Phon, number of phonemes. ${ }^{*} p<.05$.

had significant effects on naming time (see Table 7) were cumulative frequency, frequency trajectory, imageability, conceptual familiarity, name agreement, and image agreement. (Exactly the same pattern of results was found when object verification times were not included in the regression equation.) There was no reliable contribution of verification times to naming speed. ${ }^{5}$

Analysis of "yes" responses. The regression analyses reported above for the "no" responses in Multiple Regression Analysis 1 were also performed on the "yes" responses to the nonexperimental items. The result of the regression was significant $\left(R^{2}=.304, p<.001\right)$, and three variables had significant effects on verification times: imageability $(\beta=.237, S E=.08, t=-2.97, p<.01)$, name agreement $(\beta=-.214, S E=.07, t=-3.05, p<.01)$, and image agreement $(\beta=-.323, S E=.069, t=-4.67$, $p<.001)$. It would appear that, depending on the nature of the response ("yes"/“same" vs. "no"/"different"), the levels of processing engaged by the verification task differ somewhat. When participants verify that a concept evoked by a printed name is the same as the one depicted by a picture, they may mobilize more processing levels than when the concept evoked by the name is different from that represented by the picture. This differential effect suggests that in the former case the name of the target

Table 6

Results of Experiment 3: Multiple Regression Analysis 1 (of Word-Picture Verification Times)

\begin{tabular}{lrlrc}
\hline \multicolumn{1}{c}{ Variable } & \multicolumn{1}{c}{$\beta$} & \multicolumn{1}{c}{$S E$} & \multicolumn{1}{c}{$t$} & $p$ \\
\hline Cumulative frequency & -.124 & .086 & -1.435 & .153 \\
Frequency trajectory & .145 & .085 & 1.706 & .090 \\
Imageability* & -.064 & .084 & -.767 & .444 \\
Conceptual familiarity* & .049 & .100 & .488 & .626 \\
Name agreement** & -.017 & .072 & -.233 & .816 \\
Image agreement** & -.172 & .075 & -2.304 & .022 \\
Visual complexity** & .000 & .081 & -.002 & .998 \\
Number of phonemes & -.099 & .075 & -1.321 & .188 \\
\hline${ }^{*}$ Taken from Bonin, Méot, et al. (2003). & ${ }^{* *}$ Taken from Alario and Fer- \\
rand (1999). & & \multicolumn{4}{l}{}
\end{tabular}

picture is accessed and checked against the printed name, whereas in the latter case the decision may be made at a prenaming, semantic level.

\section{Discussion}

The findings from Experiment 3 are clear and have straightforward theoretical implications. In the multiple regression analyses of "different" RTs in the object verification task, the only reliable determinant of verification speed was image agreement; neither AoA (operationalized as frequency trajectory) nor word frequency had any significant effect. It is reasonable to assume that image agreement affects access to the stored structural representations (Humphreys et al., 1988) that are responsible for object recognition. Image agreement also makes a reliable contribution to object naming latencies, a result that has been found by a number of previous naming studies (Barry et al., 1997; Bonin et al., 2002; Chalard et al., 2003; Cuetos et al., 1999; Snodgrass \& Yuditsky, 1996). The most likely explanation of this result is that image agreement has its primary effect at the stage of object recognition, which is then "passed on" and detected in naming times. However, it might be argued that ratings of image agreement potentially index lexical processing, which would be problematic for our explanation. We performed a regression analysis of the Bonin et al. (2004) word reading latencies with the inclusion of image agreement as a predictor variable (together with the variables used by Bonin et al., 2004), and this revealed that image agreement had no reliable influence on word naming, which suggests that it is a variable that does not activate lexical processes. Word-picture verification and object naming are tasks that logically require the perceptual identification of objects, and, importantly, we found that image agreement - a variable assumed to index access to stored structural descriptions - makes a reliable contribution to both verification and naming times, which is precisely what is predicted if the two tasks engage the common process of object recognition. 
Table 7

Results of Experiment 3: Multiple Regression Analysis 2 (of Naming Times)

\begin{tabular}{lrcrc}
\hline \multicolumn{1}{c}{ Variable } & \multicolumn{1}{c}{$\beta$} & \multicolumn{1}{c}{$S E$} & \multicolumn{1}{c}{$t$} & \multicolumn{1}{c}{$p$} \\
\hline Verification times & .051 & .060 & .86 & .391 \\
Cumulative frequency & -.240 & .072 & -3.33 & .001 \\
Frequency trajectory & .176 & .071 & 2.47 & .014 \\
Imageability* $_{\text {Conceptual familiarity* }}^{*}$ & -.205 & .070 & -2.94 & .004 \\
Name agreement $^{* *}$ & -.206 & .083 & -2.49 & .014 \\
Image agreement** $_{\text {Visual complexity** }}^{* *}$ & -.225 & .059 & -3.78 & .000 \\
Number of phonemes & -.170 & .063 & -2.70 & .007 \\
\hline
\end{tabular}

*Taken from Bonin, Méot, et al. (2003). ${ }^{* *}$ Taken from Alario and Ferrand (1999).

The multiple regression analysis of the naming times (taken from Bonin et al., 2002) to the objects used in Experiment 3 shows that there were significant effects of AoA and frequency in addition to those of familiarity, imageability, and image agreement. Since AoA and frequency had no effect on verification times, we can conclude that the AoA and frequency effects observed in naming times result from processes that operate after those involved in accessing the visual, structural, and/or conceptual representations required for object recognition. Of course, this interpretation does not imply that effects of AoA (or frequency) can never be observed in object identification tasks (and, indeed, Experiment 1 revealed a small AoA effect on object recognition times). However, we suggest that AoA effects on naming times are not simply the result of confounds due to ease of object recognition.

\section{GENERAL DISCUSSION}

Two tasks were used to examine whether or not AoA affects object recognition in order to address the concern raised by Levelt (2002) regarding the AoA effects on picture naming reported by Barry et al. (2001) and Bonin et al. (2001). In Experiments 1 and 2, participants first learned a set of pictures and then performed a recognition memory task in which the critical experimental items all required a "new" response. In Experiment 3, participants performed a printed word-picture verification task in which the experimental items required a "no" response. As recommended by Levelt (2002), these procedures were adopted to ensure that RTs in the tasks reflect object recognition in a manner uncontaminated by possible repetition priming effects (from the learned set in the recognition memory task) or immediate semantic priming effects (from the printed words in the verification task).

In Experiment 1, we used the same factorially designed (and frequency-matched) stimuli for which Bonin et al. (2001) reported an AoA effect for both spoken and written object naming. We found that there was an effect of AoA on object recognition times, although the magnitude of this effect was smaller than that found for naming, and, when we reanalyzed the naming data from Bonin et al. (2001) including object recognition times as a covariate, the AoA effect on naming survived. This pattern of results shows that AoA does affect lexical retrieval and that, even if AoA also affects object recognition, the AoA effect on spoken naming cannot be due entirely to its having been "passed on" from an earlier stage in the overall naming process.

In Experiment 2, we again used a factorial design and operationalized AoA in terms of the frequency trajectory of the names of the objects. Zevin and Seidenberg (2002) argued persuasively that frequency trajectory provides a better test of age-limited learning contributions to lexical processing than either rated or objective measures of AoA, since it avoids the circularity problem. In Experiment 2, we selected a subset of the items used in Bonin et al.'s (2002) multiple regression study of picture naming; these items varied in frequency trajectory and were matched on cumulative frequency and many other relevant variables. We found that frequency trajectory had no effect on object recognition times but did affect naming times.

In Experiment 3, using a multiple regression design, we tested for possible effects of both frequency trajectory and cumulative frequency in the word-picture verification task using the large set of items from Bonin et al.'s (2002) picture naming study. We found that verification times (of the "different" responses) were affected only by image agreement, a variable assumed to index access to stored structural descriptions responsible for object recognition. Neither frequency trajectory nor cumulative frequency had a reliable effect on verification times, but both variables did affect picture naming times. This shows that neither the AoA effects nor the frequency effects on naming times had been "passed on" from differences in object recognition. The results of all three experiments suggest that AoA effects on object naming signal the involvement of a lexical process and not one of visual recognition.

Levelt (2002) argued that the Barry et al. (2001) and Bonin et al. (2001) studies, in which AoA effects were found, were inconclusive because they did not equate the items acquired early and those acquired late on recognition times. He suggested that these observed AoA effects on naming times might simply reflect those "passed on" from the object recognition stage, or that "recognition speed did ... the work in these experiments" (p. 669). In his critique of Alario et al.'s (2002a) study, Levelt proposed how frequency might affect object recognition. He argued that "it may well be the case that objects with infrequent names are also less often encountered and consequently less recognizable than objects with highfrequency names" (p. 668). This appears to be an eminently reasonable possibility, given that it is credible that the frequency of our use of object names in speech is related to the frequency of the objects in our experience, but Levelt offered no empirical support for it. Indeed, it is not obvious how strong the relationship between word frequency and object frequency is; there are common things that we do not often refer to, and we can use object names in speech in ways that diverge from any literal "naming" of their referents (as in metaphorical expressions such as She's a dinosaur and He gets my goat). However, it is less obvious that the AoA of object names will correlate 
highly with the age at which objects are encountered and can be recognized. Consider the items used by Barry et al. (2001), whose "early" and "late" items were matched for the rated familiarity of the objects. Barry et al.'s (2001) "late" items certainly included some that are less likely to be seen in early childhood (e.g., anchor, violin, and arrow, as well as ashtray and cigar), but then so did their "early" items (e.g., drum, elephant, leaf, and tiger, except as toys). Furthermore, their "late" items also included many items commonly found in the home (e.g., belt, envelope, lightbulb, screw, toaster, vase). (We suspect that the correlation between the AoA of objects and that of their names is weaker than the correlation between the frequency of objects and that of their names, since children may very well see and be able to recognize many objects in their homes and on television before mastering spoken language.)

Experiment 1 did show that the items from Bonin et al.'s (2001) study with names acquired earlier were recognized faster than those with names acquired later. This shows that AoA can affect object recognition, although we also showed that this cannot be solely responsible for the AoA effect on naming times (which remained significant when recognition times were covaried out). There were no reliable AoA effects on object recognition times in Experiments 2 and 3 (where AoA was operationalized as frequency trajectory), although there were AoA effects on naming times for these stimuli. The influence of AoA on object recognition is clearly less robust than it is on naming, but it is not clear why there was an AoA effect in Experiment 1 but not in Experiment 2. (A possible reason for the difference in results concerns how AoA was determined-i.e., by ratings or as defined in terms of frequency trajectory.)

Ellis and Lambon Ralph (2000) showed that connectionist networks can model age (or rather order) of acquisition effects. Indeed, their modeling work (and that developed by Monaghan \& Ellis, 2002) suggests that AoA effects should be ubiquitous when both of the following conditions apply: (1) when learning is achieved in a cumulative, interleaved manner (i.e., when, after the first items entered are learned, later items are added to the training set but the early items continue to be presented), as is the case for vocabulary acquisition; and (2) when the mappings between representations are arbitrary, or essentially item specific, as is the case for most aspects of object processing. (Zevin \& Seidenberg's, 2002, modeling work also shows that AoA effects are found when "what is learned about early patterns does not carry over to later ones" [p. 1].) It may therefore be surprising that AoA effects were not found more consistently in our recognition tasks, since object recognition involves item-specific mappings between visual-perceptual representations of the pictures and the stored structural descriptions that permit the identification of objects. Semantic classification tasks involve essentially arbitrary mappings between stored structural descriptions and semantic/conceptual representations. Morrison et al. (1992) found no effect of AoA in a categorization task in which pictures were judged as depicting natural or artificial objects, although there was an AoA effect when the same objects were named. However, Johnston and Barry (2005) did find reliable AoA effects on picture categorization in two semantic tasks; using both a "found inside or outside the house" and a "smaller or larger than a loaf of bread" classification task, they showed that objects with names acquired early were categorized faster than those with names acquired late. Naming, and spoken word production in general, involves mappings between semantic/conceptual representations and phonological word forms, and these relationships are almost completely arbitrary (for root morphemes). The fact that there are clear AoA effects in both object naming and semantic tasks, but only less consistent effects in object recognition tasks, brings into question the generality of Ellis and Lambon Ralph's "arbitrary mappings" account of AoA within connectionist models. Future work will be required to illuminate these issues further.

An important issue in the literature concerns the comparative effects of AoA and word frequency on object naming times. Contrary to what Levelt, Roelofs, and Meyer (1999) implicitly admitted, AoA and word frequency are not interchangeable, and the theoretical interpretations offered for word frequency cannot simply be transferred to those for AoA. We would argue that a serious omission of previous studies reporting frequency effects on picture naming (e.g., Jescheniak \& Levelt, 1994) is that they did not control for AoA. The results of the multiple regression analyses reported in Experiment 3 show that both AoA/frequency trajectory and cumulative frequency were strong and reliable determinants of naming latencies. Although the results of the studies reported in this article make it clear that AoA/frequency trajectory and word frequency effects are lexical in nature, their precise loci within the lexical system, and their relative influence, remain issues that require further investigation.

In conclusion, the studies reported here show that AoA effects on picture naming times have a lexical locus and are not due simply to possible confounds of object recognition times. Levelt's (2002) criticism of some picture naming studies was that they did not control for object recognition time. The results of our studies show that AoA does not have a consistent effect on object recognition times, and when we control for ease of recognition, there are still AoA effects on naming times. We submit that we have achieved an empirical resolution concerning this issue, and we interpret our results by suggesting that AoA (and word frequency) affect word retrieval in the overall naming process.

\section{REFERENCES}

Alario, F.-X., Costa, A., \& Caramazza, A. (2002a). Frequency effects in noun phrase production: Implications for models of lexical access. Language \& Cognitive Processes, 17, 299-319.

Alario, F.-X., Costa, A., \& Caramazza, A. (2002b). Hedging one's bets too much? A reply to Levelt (2002). Language \& Cognitive Processes, 17, 673-682.

Alario, F.-X., \& FERrand, L. (1999). A set of 400 pictures standardized for French: Norms for name agreement, image agreement, familiarity, visual complexity, image variability, and age of acquisition. Behavior Research Methods, Instruments, \& Computers, 31, 531-552. 
Alario, F.-X., Ferrand, L., Laganaro, M., New, B., Frauenfelder, U. H., \& SEgUI, J. (2004). Predictors of picture naming speed. Behavior Research Methods, Instruments, \& Computers, 36, 140-155.

Barry, C., Hirsh, K. W., Johnston, R. A., \& Williams, C. L. (2001). Age of acquisition, word frequency, and the locus of repetition priming of picture naming. Journal of Memory \& Language, 44, 350-373.

Barry, C., Morrison, C. M., \& Ellis, A. W. (1997). Naming the Snodgrass and Vanderwart pictures: Effects of age of acquisition, frequency, and name agreement. Quarterly Journal of Experimental Psychology, 50A, 560-585.

Bonin, P., Barry, C., MÉot, A., \& Chalard, M. (2004). The influence of age of acquisition in word reading and other tasks: A never ending story? Journal of Memory \& Language, 50, 456-476.

Bonin, P., Chalard, M., Méot, A., \& Fayol, M. (2002). The determinants of spoken and written picture naming latencies. British Journal of Psychology, 93, 89-114.

Bonin, P., Fayol, M., \& Chalard, M. (2001). Age of acquisition and word frequency in written picture naming. Quarterly Journal of Experimental Psychology, 54A, 469-489.

Bonin, P., Méot, A., Aubert, L., Malardier, N., Niedenthal, P., \& CApelle-ToczeK, M.-C. (2003). Normes de concrétude, de valeur d'imagerie, de fréquence subjective et de valence émotionnelle pour 867 mots [Concreteness, imageability, subjective frequency, and emotional valence norms for 867 words]. L'Année Psychologique, 104, 655-694.

Bonin, P., Peereman, R., Malardier, N., Méot, A., \& Chalard, M. (2003). A new set of 299 pictures for psycholinguistic studies: French norms for name agreement, image agreement, conceptual familiarity, visual complexity, image variability, age of acquisition, and naming latencies. Behavior Research Methods, Instruments, \& Computers, 35, 158-167.

Chalard, M., \& Bonin, P. (2006). Age-of-acquisition effects in picture naming: Are they structural and/or semantic in nature? Visual Cognition, 13, 864-883.

Chalard, M., Bonin, P., Méot, A., Boyer, B., \& Fayol, M. (2003). Objective age-of-acquisition (AoA) norms for a set of 230 object names in French: Relationship with psycholinguistic variables, the English data from Morrison et al. (1997) and naming latencies. European Journal of Cognitive Psychology, 15, 209-245.

Cohen, J., MacWhinney, B., Flatt, M., \& Provost, J. (1993). PsyScope: An interactive graphic system for designing and controlling experiments in the psychology laboratory using Macintosh computers. Behavior Research Methods, Instruments, \& Computers, 25, 257271.

Cuetos, F., Ellis, A. W., \& Alvarez, B. (1999). Naming times for the Snodgrass and Vanderwart pictures in Spanish. Behavior Research Methods, Instruments, \& Computers, 31, 650-658.

Cycowicz, Y. M., Friedman, D., Rothstein, M., \& Snodgrass, J. G. (1997). Picture naming by young children: Norms for name agreement, familiarity, and visual complexity. Journal of Experimental Child Psychology, 65, 171-237.

Ellis, A. W., \& Lambon Ralph, M. A. (2000). Age of acquisition effects in adult lexical processing reflect loss of plasticity in maturing systems: Insights from connectionist networks. Journal of Experimental Psychology: Learning, Memory, \& Cognition, 26, 1103-1123.

Ellis, A. W., \& Morrison, C. M. (1998). Real age-of-acquisition effects in lexical retrieval. Journal of Experimental Psychology: Learning, Memory, \& Cognition, 24, 515-523.

Holmes, S. J., \& Ellis, A. W. (2006). Age of acquisition and typicality effects in three object processing tasks. Visual Cognition, 13, 884910.

Humphreys, G. W., Riddoch, M. J., \& Quinlan, P. T. (1988). Cascade processes in picture identification. Cognitive Neuropsychology, 5, 67-103.

Jescheniak, J. D., \& Levelt, W. J. M. (1994). Word frequency effects in speech production: Retrieval of syntactic information and of phonological form. Journal of Experimental Psychology: Learning, Memory, \& Cognition, 20, 824-843.

Johnston, R. A., \& BARRY, C. (2005). Age of acquisition effects in the semantic processing of pictures. Memory \& Cognition, 33, 905-912.
Kroll, J. F., \& Potter, M. C. (1984). Recognizing words, pictures, and concepts: A comparison of lexical, object, and reality decisions. Journal of Verbal Learning \& Verbal Behavior, 23, 39-66.

LACHMAN, R. (1973). Uncertainty effects on time to access the internal lexicon. Journal of Experimental Psychology, 99, 199-208.

Lachman, R., Shaffer, J. P., \& Hennrikus, D. (1974). Language and cognition: Effects of stimulus codability, name-word frequency, and age-of-acquisition on lexical reaction time. Journal of Verbal Learning \& Verbal Behavior, 13, 613-625.

Lété, B., Sprenger-Charolles, L., \& Colé, P. (2004). MANUleX: A grade-level lexical database from French elementary school readers. Behavior Research Methods, Instruments, \& Computers, 36, 156166.

Levelt, W. J. M. (2002). Picture naming and word frequency: Comments on Alario, Costa and Caramazza. Language \& Cognitive Processes, 17, 663-671.

Levelt, W. J. M., Roelofs, A., \& Meyer, A. S. (1999). A theory of lexical access in speech production. Behavioral \& Brain Sciences, 22, 1-75.

Levelt, W. J. M., Schriefers, H., Vorberg, D., Meyer, A. S., Pechmann, T., \& Havinga, J. (1991). The time course of lexical access in speech production: A study of picture naming. Psychological Review, 98, 122-142.

Monaghan, J., \& Ellis, A. W. (2002). What exactly interacts with spelling-sound consistency in word naming? Journal of Experimental Psychology: Learning, Memory, \& Cognition, 28, 183-206.

Moore, V., Smith-Spark, J. H., \& Valentine, T. (2004). The effects of age of acquisition on object perception. European Journal of Cognitive Psychology, 16, 417-439.

Morrison, C. M., Ellis, A. W., \& Quinlan, P. T. (1992). Age of acquisition, not word frequency, affects object naming, not object recognition. Memory \& Cognition, 20, 705-714.

New, B., Pallier, C., Ferrand, L., \& Matos, R. (2001). Une base de données lexicales du français contemporain sur Internet: LEXIQUE. L'Année Psychologique, 101, 447-462.

OldField, R. C., \& WingField, A. (1965). Response latencies in naming objects. Quarterly Journal of Experimental Psychology, 17, 273281.

Perea, M., Rosa, E., \& Gómez, C. (2002). Is the go/no-go lexical decision task an alternative to the yes/no lexical decision task? Memory \& Cognition, 30, 34-45.

Snodgrass, J. G., \& Vanderwart, M. (1980). A standardized set of 260 pictures: Norms for name agreement, image agreement, familiarity, and visual complexity. Journal of Experimental Psychology: Human Learning \& Memory, 6, 174-215.

Snodgrass, J. G., \& Yuditsky, T. (1996). Naming times for the Snodgrass and Vanderwart pictures. Behavior Research Methods, Instruments, \& Computers, 28, 516-536.

Vitkovitch, M., \& Tyrrell, L. (1995). Sources of disagreement in object naming. Quarterly Journal of Experimental Psychology, 48A, 822-848

WingFIELD, A. (1968). Effects of frequency on identification and naming of objects. American Journal of Psychology, 81, 226-234.

ZENO, S. (ED.) (1995). The educator's word frequency guide. Brewster, NJ: Touchstone Applied Science Associates.

Zevin, J. D., \& Seidenberg, M. S. (2002). Age of acquisition effects in word reading and other tasks. Journal of Memory \& Language, 47, 1-29.

\section{NOTES}

1. Of course, if "recognition speed did do the work" in reports of frequency and/or AoA effects on naming times, then this would tell us something about object recognition: The effects would simply be relocated from lexical retrieval to object recognition.

2. Object decision times are not always as long as naming times. For example, Moore et al. (2004) presented pictures (for $200 \mathrm{msec}$ ) sandwiched between forward and backward masks (composed of "a montage of overlapping discontinuous image parts") and encouraged participants to respond as quickly as possible. This procedure resulted in mean object 
decision latencies that were shorter than those typically seen for object naming, but Moore et al. did not compare naming times under the same conditions.

3. It could be argued that in cascade models, in which activation is transmitted in a nonlinear fashion to later phases, a small AoA effect at the early phase of object identification would be inflated at the later phase of lexicalization. However, the results of our Experiments 2 and 3 , which found no reliable AoA effects on object identification but did find reliable effects on picture naming, are inconsistent with such an explanation. We thank an anonymous reviewer for having pointed this out to us.
4. In ratings of object familiarity, raters are instructed to see familiarity as the "degree to which you come into contact with, or think about, the thing depicted" (Barry et al., 1997, p. 566). This variable has been thought to be equivalent to lexical familiarity or subjective frequency (i.e., ratings of how often people believe a word occurs in their experience) as opposed to the objective frequency with which words actually occur in large sample of text.

5 . With the exception of objective word frequency and familiarity, which were not significant, the same results were obtained when ratings of AoA (Alario \& Ferrand, 1999) and adult frequencies (New et al., 2001) were used.

\begin{tabular}{ll}
\multicolumn{2}{c}{$\begin{array}{c}\text { List of the Words Used in Experiment 2 } \\
\text { (and Primary English Translations) }\end{array}$} \\
\hline \multicolumn{1}{c}{ Frequency Trajectory } \\
\hline High to Low & \multicolumn{1}{c}{ Low to High } \\
\hline âne (donkey) & ampoule (lightbulb) \\
ballon (balloon) & bougie (candle) \\
canard (duck) & bouteille (bottle) \\
carotte (carrot) & cadenas (padlock) \\
chien (dog) & canapé (couch) \\
clou (nail) & canon (cannon) \\
clown (clown) & casquette (cap) \\
cochon (pig) & cerf (deer) \\
crocodile (crocodile) & chemise (shirt) \\
escargot (snail) & cigare (cigar) \\
fraise (strawberry) & cigarette (cigarette) \\
gâteau (cake) & ciseau (scissors) \\
hibou (owl) & cloche (bell) \\
lapin (rabbit) & couronne (crown) \\
moto (motorcycle) & cravate (tie) \\
oiseau (bird) & cygne (swan) \\
panier (basket) & échelle (ladder) \\
parapluie (umbrella) & fenêtre (window) \\
phoque (seal) & harpe (harp) \\
poisson (fish) & oeil (eye) \\
pomme (apple) & pantalon (trousers) \\
renard (fox) & piano (piano) \\
serpent (snake) & règle (ruler) \\
tambour (drum) & scie (saw) \\
tomate (tomato) & train (train) \\
tortue (turtle) & valise (suitcase) \\
\hline & \\
\hline &
\end{tabular}

(Manuscript received March 11, 2004; revision accepted for publication May 31, 2005.) 